\title{
Assessing the impact of students facilitating workshops within the context of a collaborative cross institution project
}

\author{
Grant Petrey, University for the Creative Arts
}

\begin{abstract}
This research was conducted to evaluate the impact that situated collaborative learning projects can have on the experience of students who lead workshops as student facilitators. Following the 'Communities of Practice' work of Lave and Wenger (1991), this cross institution project was developed in conjunction with the University for the Creative Arts (UCA) in Kent, and Turner Contemporary, Margate, and Charles Dickens School. Secondary school, further education and higher education students produced animation work from source materials obtained from the Margate Community in a series of short workshops. These workshops were facilitated by mixed stage student volunteers from the BA (Hons) Animation Arts course, School of Fine Arts at UCA. The impact of this project on the student experience as a strategy for enhancing critical skills and improving self-efficacy is considered via qualitative research yielded from student feedback. The results revealed the approaches used by the student facilitators in managing the learning of others and a range of cognitive and meta-cognitive strategies which they deployed, including evidence of scaffolding.
\end{abstract}

Keywords: Peer Assisted Learning; scaffolding; student facilitation.

\section{Introduction}

This animation project was situated outside the confines of the University for the Creative Arts (UCA) and therefore presented an opportunity to develop pedagogic research around experiential and active situated learning (Lave \& Wenger, 1991). The collaboration between educational institutions with a common project also opened up further pedagogic research possibilities. Within the area of animation and fine art, a cross institution and cross learning stage 'community of practice' (Wenger, 1998) was piloted as a case study for further development. This case study contributed to informing the revalidation of courses within the School of Fine Arts by providing an insight into how collaboration with other institutions can impact on teaching and learning. It provided information to help gauge the logistics of how to implement cross-site learning activities. The work produced by students was displayed in June 2012 as part of two site-specific installations co-commissioned by UCA, Turner Contemporary, Margate, and the Arts Council for England by Mark Wallinger and Lindsay Seers.

Using the Peer Assisted Learning (PAL) model as a premise for creating a 'community of practice', mixed stage higher education students acted as facilitators to run workshops with learners from further and secondary education. The student facilitators were prepared in advance of delivering the workshops, and student voice around their attitudes to teaching and learning and their expectations of the event were elicited via questionnaires and discussion before and after the workshop sessions. 
The results from the project revealed the approaches used by the student facilitators in managing the learning of others. They developed a range of cognitive and meta-cognitive strategies, and evidence of 'scaffolding' (Holton \& Clarke, 2006) was clearly demonstrated. Students revealed interesting perceptions about what they considered important qualities for an educator to possess, which were strongly linked to having good social skills and empathy for their learners.

\section{Background}

The influential premise endorsed by developmental psychologist Lev Vygotsky (1978) that all learning takes place socially and collaboratively formed the starting point of this research project via the 'Communities of Practice' work of Jean Lave and Etienne Wenger (1991). The literature review opened up a vast number of social constructivist approaches to pedagogy that have been influenced by, or concur with, Vygotsky and have since been developed or challenged through research. For the purpose of this study, an overview of the literature in relation to Peer Assisted Learning (PAL) schemes is considered, with a focus on the impact that PAL has on the peer tutor or facilitator.

Vygotskyian social constructivist approaches to teaching and learning, position the learner in a social learning environment where they are active in constructing their own responses and knowledge, with guidance. The aim of this approach is to engage learners with critical thinking so that they can become increasingly effective in negotiating a range of problems and scenarios (Rogoff, 1990; Zimmerman, 1995; Holton \& Clarke, 2006). There are conflicting views about the effectiveness of social constructivist pedagogic strategies for achieving deep transformative learning, however collaborative learning in its' various forms, and in particular PAL from social constructivist approaches, build upon Vygotsky's learning concept of the Zone of Proximal Development.

The Zone of Proximal Development is widely acknowledged and used as a teaching method that has lead to the term 'scaffolding' (Bruner, 2006). Scaffolding is used to introduce new problems, concepts and skills to the learner that are just beyond their current learning level. They can then be given support through various forms of scaffolding which allow the learner to acquire and assimilate new knowledge and skills.

Scaffolding is a methodology central to PAL. Holton and Clarke (2006) give a complex overview of scaffolding processes, roles and contexts through a range of studies. Expert, Reciprocal and Self Scaffolding are identified:

- Expert Scaffolding: an active role of supporting and structuring the learning process.

- Reciprocal Scaffolding: an exchange of knowledge and skills amongst learners with interchangeable roles of support where 'scaffolder' becomes 'scaffoldee' and vice versa.

- Self Scaffolding: the independent internal process of meta-cognitive and cognitive learning via reflection (also known as self-regulated learning).

Various PAL initiatives that utilize scaffolding methodologies exist in a multitude of contexts across UK higher education (HE) and tend to follow the model founded in the USA at the 
University of Missouri, known as Supplementary Instruction (SI), established by Dr Deanna Martin in 1973. PAL schemes usually consist of students with a higher skill level or stage of learning, instructing other learners within their study subject domain. PAL schemes follow SI by focusing on assisting lower level stage learners to acquire technical skills relevant to their course of study and helping them to navigate the expectations of the course and its requirements. This has lead to studies which examine the impact and effectiveness of PAL schemes to ascertain the quality of learning taking place (for examples, see Boud et al., 2001; Ashwin, 2003a, 2003b; Capstick, 2004; Roscoe \& Chi, 2007; Ludewig \& Dunne, 2010).

Falchikov's (2001) guide to PAL within HE defined four main types of collaborative learning within PAL initiatives which employ different approaches to scaffolding:

1. Same level learning with a flattened structure, where learners have equally matched skills and knowledge but support learning through the sharing of ideas, approaches and skills via group working and discussion.

2. Same level learning where there is a diagnosis by a tutor of unequal learner skill, knowledge or ability. This information is used strategically to utilise 'scaffolding' methodology so that student groups are formulated and a learner acts as a lead instructor for the benefit of the other learners.

3. Cross level learning activities within an institution where higher learning level students facilitate lower level learners within the same subject area of study using scaffolding (based on the SI model).

4. PAL activities that cross learning levels and institutions wherein undergraduate learners assist learning within a school or further education college within the subject area.

This final form of peer learning involving cross level/cross institutional collaboration is explored by this case study, within an Arts context. The focus of the research is the experience of the learners who facilitated this cross learning level and cross institution PAL activity.

Previous research generally concludes that PAL has a positive impact (Boud et al., 2001). Providing the correct support and training to peer tutors and facilitators is agreed by most PAL schemes, but more specific research into the context of PAL and nature of the 'scaffolding' methodology has raised some issues. Previous research focuses on the context of the PAL activities and the effectiveness of the various scaffolding methods that range from 'soft' to 'hard' (Brush \& Saye, 2002). Scaffolding exercises that are deemed to be 'hard' require the most structured sessions to support, guide and check learning progress. The effectiveness of scaffolding for deep cognitive learning is explored in the literature. Learning is categorised into surface learning, strategic learning and deep cognitive learning, where cognitive transformation takes place due the learning activity. Criticism of PAL is centred on concerns that it fosters a superficial or a strategic process of learning. The systematic process of PAL creates a dogmatic approach so that learners can meet the curriculum requirements and expectations of a course, rather than truly engaging with the social constructivist aim of acquiring quality, deep cognitive developmental learning (Ashwin, 2003a; Capstick, 2004; Roscoe \& Chi, 2007; Ludewig \& Dunne, 2010). 
Whilst the literature examining the impact of PAL on the cognitive development of the tutor or facilitator within an HE context is not as prolific as other learning stages, what is evidenced is very positive, and pedagogic research into this area has increased (Topping, 2005). 'Learning by teaching' initiatives have been carried out in secondary schools and were found to have a positive impact upon learners (Bargh \& Schul, 1980; Annis, 1983). For example, Annis (1983) conducted an often cited 'teaching as learning' study with school children, where the benefits of PAL for the facilitating tutor were considered. The study compared the test results of three groups on the same information. Annis asserts that learning test scores were highest amongst those who had engaged in peer teaching because not only did the students become more active in the learning process, but that they had to negotiate "such essential learning tasks as giving the information, organisation and structure, grouping or chunking the material to be learned into smaller groups and forming rich associations between the new material and things they already knew" (p.46 ${ }^{1}$ ). More recent literature concurs with Annis (Hartman, 2001; Zimmerman, 1990; Lave \& Wenger, 1991; Marton \& Trigwell, 2000; Gillies \& Ashman, 2003; Topping, 2005: Miller et al., 2010) and identifies that the key factor in promoting higher level cognitive activity is active reflection and self-questioning required in preparation that is undertaken by the peer tutor to facilitate or teach peers. This preparation for PAL involves higher cognitive or 'meta cognitive' skill, which involves thinking about how and when to use strategies of planning, monitoring and evaluating. This helps to build on existing knowledge and experience and improves the cognitive skills of differentiating, selecting, storing, applying, justifying and responding (Hartman, 2001).

Ashwin (2003a) has published results that have been sceptical of PAL for encouraging strategic learning, however, elsewhere he asserts the benefits of PAL on learners who facilitate PAL sessions. He finds that transformative learning takes place because peer facilitators emerge with a greater awareness of their own learning and the context of learning as a social activity. From his data he states that the peer learning process evidenced "changes in their views of what is important in learning," (p.12). He elaborates that peer tutors are more likely to engage with and value learning within different social scenarios rather than learning as an individual. Drawing upon earlier studies by Abercrombie, 1960; Eraut et al., 1975; Heron, 1989; Rowland, 1993 (all cited in Ashwin, 2003b), Ashwin is positive about the impact that changing roles and responsibilities within learning can have. This concurs with the more detailed work of Holton and Clarke (2006) and their complex view of scaffolding relationships and contexts.

The complexities of scaffolding and the interchangeable position of the learner within collaborative learning scenarios are central to the literature produced by Lave and Wenger (1991); Rogoff, (1990); Wenger, (1998); and Holton and Clarke (2006). There is much interest in the ideas linked to Vygotsky's 'Zone of Proximinal Development'. Rogoff (1990) uses the term 'Apprenticeship in Thinking' which explores the importance of social and institutional scaffolding relationships in relation to structured teaching or guided participation. Lave and Wenger (1991) coined the term 'Communities of Practice' where the social and collaborative aspects of learning are important. Their work into situated learning focuses on how social interactions function and how they can be reviewed and reorganised within learning for more inclusive, situated and effective participation. This research outlines a move away from performance-related learning goals that can foster competitive approaches, and moves towards 
identifying performance levels so that skills can be developed. The learner is 'scaffolded' so they become more aware of their skills and what they can achieve.

Within collaborative learning environments, the PAL tutor is offered the opportunity to understand different learning contexts and viewpoints and to consider the interplay of expert, reciprocal and self-scaffolding. For peer tutors or student facilitators, PAL offers the opportunity to understand different contexts and viewpoints with the change of role from learner into tutor. The peer tutor or student facilitator role creates a context of responsibility which encourages reflection and responses with increased criticality.

It is interesting to note that some studies advocate that the facilitators of PAL should be learners who have previously demonstrated the positive characteristics aligned with best practice teaching (for example, positivity, motivation, organization and developed social and interpersonal communication skills). However, literature cited by Topping (2005) describes school learners who were actively disengaging with the learning process and who were socially disruptive. They were given peer learning facilitator roles and subsequently demonstrated positive changes. Students with learning barriers and disabilities have also benefited from collaborative learning by taking a peer facilitator role around the transfer of social skills.

\section{Method}

This project took place at the University for the Creative Arts (UCA), Kent in 2011. Cross stage learners from the BA (Hons) Animation Arts course (situated in Maidstone) were asked via email to volunteer to participate in two, one day animation workshop events. Twenty two selfselecting students from a cohort of 60 volunteered. The age range of participants ranged from $19-23$ years.

The workshops involved the higher education (HE) students acting as peer facilitators working with secondary school and further education (FE) learners. The project involved them facilitating these students to work together to develop ideas and teach some specific animation techniques and technology skills which, in turn, helped the learners realise their ideas.

The UCA ethics protocol was explained to the learners and it was made clear that participation with data gathering exercises was not compulsory or a condition of taking part in workshop events. All volunteering participants who wished to contribute to the research were asked to sign a consent and confidentiality form.

In preparation for the workshops, volunteer students were given a questionnaire to elicit responses about their expectations of the workshop event and their perceptions of quality teaching and learning. This information was then used in a preparatory session to address their role; the importance for clarity of communication in delivering learning aims and objectives; and the protocol explaining the action they should take if any issues arose or they encountered any personal compromise or discomfort.

The first workshop session was with two groups of FE learners studying a vocational art and design course. The session was part of a curriculum lesson. Each FE group comprised of 20 
students with an age range of 17-19 years. Volunteer facilitator HE students had a supporting role in the classroom: a team of 3 teachers and technical support staff lead the idea development and delivery of new technical skills in animation. This provided student facilitators with the opportunity to observe, and the security of regulating their involvement in the session. This initial session was intended to act as a scaffolding session for the student facilitators.

The second workshop involved a mixed stage and mixed institution activity. The group comprised of 90 secondary school and FE learners whose ages ranged from 14-19 years. Participation in this session was voluntary, and it was not aligned to any course requirements. The session was managed and supported by 4 cross institution staff members. Staff members organised the 90 learners into 15 mixed stage and cross institution groups comprising of 6 learners (generally made up of 3 secondary school and 3 FE learners). Each learning group was assigned at least one of HE student facilitator. All 15 groups worked in a large area and were assigned a collaborative workspace within close proximity to each other.

Workshop sessions involved student facilitators developing ideas in relation to the project theme of 'Experiences and stories about the sea'. Demonstration, instruction and coaching were used to introduce the students to technical workshops so they could use technology and software, as well as the principles of animation techniques to help them realise their ideas within the constraints of an afternoon workshop session.

The project was a small-scale research activity, where the scope was limited to two mixed learning stages and cross institutional learning events. The project is therefore not a comprehensive study and would benefit from longitudinal research. The case study was carried out in an exploratory context of forming new collaborative relationships with other creative sector partners, with the key aim of enhancing student learning experiences and opportunities. Given the exploratory nature, it was anticipated that this project would reveal future directions for research.

Learners were given the opportunity to engage with a reflective cycle so they could plan and articulate their responses. Reflective cycles such as the 'Kolb Cycle' (Kolb, 1984) encourage a mastery of performance via reflection rather than aiming to achieve specific goals. The volunteer student facilitators were informed of all aspects of planning and preparation for the workshop events, to help them position their role and enable them to reflect upon their own actions, responses and perceptions, along with the overall process.

The nature of this research was qualitative: data gathering took the form of questionnaires and focus group discussion which encouraged the student facilitators to share their observations and perceptions of their experiences. The examination of student facilitators' perceptions and changes in these perceptions focused on two areas:

1. What they considered to be important factors for quality learning to take place and what action they took to enact these.

2. How they responded to the student facilitator role and if they employed any coping strategies. 
By focusing on these two areas it was intended that the evidence could be generated into the meta-cognitive and cognitive processes used by the student facilitators when reflecting upon their experiences. From this evidence we could begin to evaluate the impact of the student facilitation project.

The questionnaire data was used as primary data to evaluate the impact of the workshop sessions on the peer facilitators. The data was assessed for evidence 'self-scaffolding' or self-regulation (where the peer facilitators were able to demonstrate their cognitive processes in relation to managing the learning of others). From their perceptions of the event, any strategies or responses that were developed or employed during the workshop sessions were examined for examples of meta-cognitive activity. Evidence of meta-cognitive skill or activity involved the students being able to articulate from their experiences that they were thinking about the skills that needed to be applied to manage the learning process. Evidence of when and how they employed strategies for learning demonstrated evaluation and the utilization of their cognitive skills (Hartman, 2001). Using the gathered data, the students' perception of self-efficacy and any changes that occurred linked to the peer mentoring exercise were examined.

Whilst care was taken to ensure that the questions were not leading, it is acknowledged that they could lead to biased responses due to the prior working relationship between the participants and the research initiator. In an attempt to minimise this, the questionnaires were submitted anonymously to encourage openness. The focus group session that followed was relatively unstructured to encourage students to discuss their experiences. Occasional prompting ensured all participants could express themselves and that the group was not dominated by the views of only some of the group. Again, whilst these prompts were not intended to steer or bias the responses, it is possible the prompts had an impact on their responses.

\section{Findings}

To evaluate the extent that 'teaching as learning' had on the HE learners in their role as peer facilitators in this small scale mixed stage and cross institution animation workshop, I will focus on examples of meta-cognitive activity evidenced by the peer facilitators in conjunction with any changes that can be measured against a change in their perceptions to teaching and learning and to self efficacy.

In general the student facilitators agreed it was a positive personal experience. They were able to express an awareness of the limitations of the project due to time, and were keen that any future events should run over a longer duration. This would suggest that the peer facilitators enjoyed the experience. They also had suggestions about how it could have been more successful.

Within their groups some facilitators were able to identify the exchange of learning or 'scaffolding' taking place between the different ages within the groups. The 'scaffolded' learning was either Expert Scaffolding, where the FE learners taught the secondary school learners, or Reciprocal Scaffolding, where approaches by both age groups were beneficial to the process.

'The older students seemed to take charge more than the younger two but they got into it eventually. They seemed to communicate to each other well'. 
I simply explained how to use the programs and equipment. They seemed a little apprehensive to use the equipment but once they watched the further education students they found it fun and enjoyable. The only problem I had was getting the further education students to let the learners have a go!'

'In some cases, the school children were more experimental while the further education students were quite figurative in approach, so these two approaches complemented each other well, despite the age differences'.

There was an instance were one of the student facilitators needed advice from another facilitator. A positive decision was made about seeking advice for the best way forward that would suggest meta-cognitive activity to implement a more successful strategy. However the statement also reveals some issues around negative self-efficacy being linked to perceptions and expectations of the 'expert' teacher.

'I find talking in front of people I do not know difficult so this has helped me with that. I found myself asking others for help instead of already knowing the answers. I feel I need to take a step back and learn more myself before trying to teach others'.

Other observations and views relating to the success of the scaffolding process between the mixed stage context of the workshops that included secondary and FE learners were expressed. Student facilitators supplied inconclusive data about the success of this element, but some expressed problems that impacted on how they managed the learning process.

'I now know that teaching students of a younger age is easier than trying to teach those closer to my age'.

'I think teaching mixed age groups could be successful if there were longer workshops, over a few days, for example, as then they'd get the opportunity to get to know each other a bit better and feel more comfortable'.

The student facilitators were asked about the role of an educator and the qualities they perceived were important in an educator. Although the overall response is from a small sample, the most recurring response was 'patience' followed by 'knowledge'. However, aside from knowledge, a range of closely related interpersonal communication skills were expressed, with 'tolerance' being the next most recurring response, and 'leadership' 'fairness' and 'charisma' also being mentioned. This would suggest that interpersonal communication skills and empathy based around student-centred approaches to teaching and learning were important to the peer facilitators and their perceptions of facilitating learning. They also saw the educator role as someone who 'helps, guides, inspires, and gives confidence'. This would also suggest perceptions of the educator role linked to helping learners develop self-efficacy rather than purely relaying information. 
When expressing their expectations of the workshop event, one of the most recurring negative themes was anxiety around interpersonal skills due to a lack of confidence or ability, or that there would be difficulties learners with learners.

'Hope no students are mean/nasty'.

'Some of the students might behave badly, but I can cope'.

'Doubt in my own abilities'.

Positive themes that emerged in facilitators' expectations were linked to the social experience of learning.

\section{'A fun environment, an inspiring time, an opportunity to be creative'.}

'I think it will go well, [it] is an interesting and creative activity and it is very interactive rather than a lecture'.

'To meet new people, pass on skills'.

One of the aims of the workshop project was to extend collaboration between institutions and therefore this may have prompted social expectations about the nature of the project. However, both positive and negative expectations of the workshop were aligned with the social, as advocated by social constructivist literature (Vygotsky, 1978; Rogoff, 1990; Zimmerman, 1995; Holton \& Clarke, 2006).

Student facilitators were able to identify problems that the secondary school and FE students were having, and responded by intervening. Many of the facilitators used similar methods to intervene when they found that the students had problems planning and communicating. Overall there is a lack of detail in the evidence provided about the strategies they used to support the learners with their planning issues, and responses are generalised to 'encouraging' and 'motivating' the learners. Whilst it is important is encourage learners, these would be regarded as surface responses, but there was evidence of cognitive strategies being deployed to engage the learners. Some students acknowledged the barriers that were preventing the learners from progressing and took action to reorganise the groups. The facilitators either split the initial group of 6 into separate sub groups based on age, institution or gender relating to the barrier that was preventing collaborative progress with the practical tasks.

'My group worked well. I split them into two teams who made separate work as some of the girls were a bit stroppy about working with the boys. So it turned out well eventually'.

'When I tried to get them to talk as a group about ideas they originally seemed reluctant, until they divided into a group of boys and a group of girls, and then they seemed more comfortable discussing ideas amongst themselves, and I could just give them advice on how and what they should consider doing'. 
This would also suggest that the facilitators were able to acknowledge the social context of learning and respond to it using meta-cognitive processes to facilitate learning. Some facilitators demonstrated more acute observations which they were able to use for more effective responses.

'Since ' $X$ ' was the strongest link in the group, we decided to approach her and give her the 'secret' role of leading the group'.

The facilitator expands:

'The other roles in the production were given and roles changed around person to person'.

What is interesting is that this facilitator demonstrated some negative self-efficacy prior to the workshop by expressing doubts about their ability, and described themselves as having 'mid/low' confidence and getting nervous. Their statement about how they managed the learning process demonstrates meta-cognitive processing by employing strategic cognitive skills so that the learning experience is managed more effectively. The students are not just re-organised, but given strategic roles. Here the facilitator differentiated between abilities within the group and also set tasks to utilize this difference whilst also keeping learners actively engaged. Conversely, some of the facilitators struggled to find progressive strategies to engage the learners and suggested the learners could have been engaged to a greater extent by 'making groups smaller' or they if they had 'more people to help' each group.

There were other limited examples which demonstrated that the facilitators were engaged with the process of effective teaching that could point towards meta-cognitive processing or attempts to question what the best strategies for communication were.

It has changed my perspective on teaching more than anything, [....] and trying to explain something that I do every day is difficult but interesting all the same. Remembering small details and such'.

'Young learners do not want to listen to overly complicated directions, and would rather take charge without being ordered. So I had to simplify when explaining the technical details and provide them with basic ideas for them to then expand upon'.

The later statement demonstrated the role of the facilitator as an expert scaffolder who made judgments about the needs of the learners and then applied a strategy. This demonstrated thinking into how best to employ their cognitive skills of describing, demonstrating and supporting the learning process.

\section{Conclusions}

The findings concurred with the results in the literature review (Vygostsky, 1978; Lave \& Wenger, 1991; Topping, 2005). What was most apparent from the findings was that the student facilitators perceived interpersonal skill and learner-centred approaches as important factors for successful teaching. The findings elucidated from the study group demonstrated that they recognised learning as a social activity, and they were able to identify the positive aspects that 
this could have on how the learning process is managed. They were also able to identify problems and issues that arose during the learning process. The challenge created from changing roles from learner to facilitator provided a new learning situation for the students. They reported this to be a positive and beneficial personal experience for improving their communication skills and confidence.

The facilitators were able to demonstrate their perceptions of the learning event and how they responded. Strategies involving the cognitive skills of organizing, explaining and justifying were evidenced from the findings. Evidence of meta-cognitive processes were also demonstrated by managing and selecting a strategy, or rather self regulating their responses, to improve the learning process.

Whilst a range of strategies were employed by the learners and evidence of their cognitive ability was demonstrated, what the study does not show is the use of new approaches relating to cognitive skill that would confirm deep transformative learning. There is also no evidence demonstrating improved cognitive strategies or skills in the learners.

The findings of this small-scale research study are by no means conclusive and raise many other issues and areas that could be addressed with further research. The project would benefit from a longitudinal study to collate data from the peer facilitators. This would provide further data on the strategies employed by the peer facilitators when managing and organising learners to enhance the learning process and provide assessment material that could track the strategies they used.

Taking a lead from Zimmermann (1995), it would be beneficial to evaluate the responses of student facilitators involved in leading small groups with different types of learning activity. This could be extended to create opportunities which scaffold the peer facilitators into more challenging tutoring roles with learning groups who have specific learning needs or learning barriers - requiring them to formulate new strategies for delivery. Zimmerman (1995) and Rogoff (1990) argue that the self-regulation, or self-scaffolding of meta-cognitive skill in challenging situations creates deeper transformative learning for mastering skill. By correlating this longitudinal 'teaching as learning' research data with an evaluation of corresponding longitudinal research data into the peer facilitators, perceptions of their performance and their self-efficacy over the same period could be examined. Additionally, it would also be interesting to assess the impact that their peer facilitator experiences had on their attitudes towards teaching and learning over time.

Student facilitators would benefit from being made aware of their cognitive skills and the strategic responses they had through plenary sessions. This form of reflective scaffolding could help provide greater awareness of their levels of performance and aid improvement. Extending the longitudinal research to include control groups (Annis, 1983) would provide more comparative data for more conclusive results into the impact of peer assisted learning. Greater research into scaffolding strategies for collaborative cross stage learning, based on the literature by Holton and Clarke (2006), could also be explored. 
Learning projects that crosscut institutional and learning stage are difficult to organise and coordinate, but they are beneficial. The vast majority of students who participated expressed interest in taking part in future events and felt more time was needed to develop the project work. This willingness of the peer facilitators to participate and develop the collaborative project work further would suggest gains in the self-efficacy of the facilitators. However, more detailed consideration into the motivations of the self selecting facilitators could also provide interesting data. The practical application of the 'teaching as learning' workshops could also be considered beyond self-selecting students to monitor their impact as part of a credit bearing qualification. This would require a structured program of study skills to support students and give them a situated, or real world context to apply them by using 'teaching as learning' collaborative projects. The application of 'teaching as learning' and a focus of strategies that promote transformative learning outside of discipline specificity would have significant implications in challenging the ethos of many HE courses.

The project focused on the organisational aspects involved with collaborative learning to create opportunities for 'scaffolding' based on Lave and Wenger (1991), and the impact his could have on facilitators. Therefore the cross stage, and cross institute organisation were not specific to the discipline of animation and could be translated as strategies for creating communities in other subjects and learning areas. Whilst the practical nature of the animation workshops demanded interaction, which was important for linking the different institutions involved, a longitudinal study could consider the implications and impact of scalability and the role that social media may have on extending the workshops into a more complex project for documenting, monitoring and eliciting responses from the facilitators and other students. "The community creates the social fabric of learning" (Wenger et al., 2002, p.28) and online learning would decentralize the learning activities and participation which would have implications on the type of 'scaffolding' relationships that could potentially take place and how effective they may be.

An obvious area for further research would be to evaluate the impact that these collaborative sessions had on the secondary school and FE learners' perceptions of learning. Research that focused more specifically on the configuration of the student groups in the workshops and their dynamics may be revealed. A longitudinal study into the progression pathways of these learners could also be beneficial for evaluating the recruitment impact that collaborative learning events had. If these results proved to be favourable, they could justify expenditure.

Collaborative and peer assisted learning emerged positively from the findings to suggest that 'teaching as learning' can be a useful tool for engaging learners with alternative modes of learning by changing the dynamics of their learning environment and learning task. The author would assert that 'teaching as learning' should be used as one of a range of strategies to improve the student learning experience and that supportive, guided instruction to scaffold the learners is essential.

\section{References}

Annis, L.F. (1983) 'The processes and effects of peer tutoring'. Human Learning: Journal of Practical Research \& Applications. 2 (1): 39-47. 
Ashwin, P. (2003a) 'Peer support: relations between the context, process and outcomes for the students who are supported’. Instructional Science. 31 (3): 159-173.

Ashwin. P. (2003b) 'Peer facilitation and how it contributes to development of a more social view of learning'. Research in Post-Compulsory Education. 8 (1): 5-18.

Bargh. J. A. and Schul, Y. (1980) 'On the cognitive benefits of teaching'. Journal of Educational Psychology. 72 (5): 593-604.

Boud, D., Cohen, R., and Sampson, J. (2001) Peer Learning in Higher Education: Learning From and With Each Other. London: Kogan Page Ltd.

Bruner. J. S. (2006) In Search of Pedagogy Volume 1: The Selected Works of Jerome S. Bruner. New York: Routledge.

Brush, T. A. and Saye, J. W. (2002) 'A summary of research exploring hard and soft scaffolding for teachers and students using a multimedia supported learning environment'. The Journal of Interactive Online Learning. 1 (2): 1-12. Available online at: http://www.ncolr.org/jiol/issues/pdf/1.2.3.pdf (accessed $2^{\text {nd }}$ November 2012).

Capstick, S. (2004) Benefits and Shortcomings of Peer Assisted Learning (PAL) in Higher Education: An Appraisal by Students. Paper presented at the Peer Assisted Learning Conference, Bournemouth, January 2004. Available online at:

http://pal.bournemouth.ac.uk/documents/Bnfts\%20\%26\%20Shrtcmngs\%20\%20of\%20PAL3.pdf (accessed $2^{\text {nd }}$ November 2012).

Falchikov, N. (2001) Learning Together: Peer Tutoring in Higher Education. London: Routledge/Falmer.

Gillies, R. M. and Ashman A. F. (2003) Co-operative Learning: the Social and Intellectual Outcomes of Learning in Groups. London: Routledge/Falmer.

Holton, D. and Clarke, D. (2006) 'Scaffolding and Metacognition'. International Journal of Mathematical Education in Science and Technology. 37 (2): 127-143.

Hartman, H. J. (2001) Metacognition in Learning \& Instruction: Theory Research and Practice. Dordrecht, The Netherlands: Kluwer Academic Publishers.

Kolb, D. A. (1984) Experiential Learning Experience as a Source of Learning and Development. New Jersey: Prentice Hall.

Lave, J. and Wenger, E. (1991) Situated Learning: Legitimate Peripheral Participation. Twelfth Edition. New York: Cambridge University Press.

Ludewig, A. and Dunne, T. (2010) Improving student engagement through a structured peer support program involving international students. Paper presented at TL Forum (2010). 
Educating for sustainability. Proceedings of the 19th Annual Teaching Learning Forum, 28-29 January 2010. Perth: Edith Cowan University. Available online at: http://otl.curtin.edu.au/tlf/tlf2010/contents-all.html

Marton, F. and Trigwell, K. (2000) 'Variatio est Mater Studiorum'. Higher Education Research and Development. 19 (3): 381-395.

Miller, D., Topping, K. J. and Thurston, A. (2010) 'Peer tutoring in reading. The effects of role and organization on two dimensions of self esteem'. British Journal of Educational Psychology. 80 (3): 417-433.

Roscoe, R. D. and Chi, M. T. H. (2007) 'Understanding tutor learning: knowledge-building and knowledge-telling in peer tutors' explanations and questions'. Review of Educational Research. 77 (4): 534-574.

Rogoff, B. (1990) Apprenticeship in Thinking: Cognitive Development in a Social Context. New York: Oxford University Press.

Topping, K. J. (2005) 'Trends in peer learning'. Educational Psychology: An International Journal of Experimental Educational Psychology. 25 (6): 631-645.

Vygostsky, L. (1978) Interaction between Learning and Development. From Mind and Society (pp79-91). Cambridge, MA: Harvard University Press. Reprinted in Gauvain, M. \& Cole, M. (eds) (1997). Readings on the development of children. Second Edition. New York: W H Freeman \& Company. Available online at: http://www.psy.cmu.edu/ siegler/vygotsky78.pdf (accessed 2nd November 2012).

Wenger, E. (1998) Communities of Practice: Learning, Meaning, and Identity. Cambridge: Cambridge University Press.

Wenger, E., McDermott, R. A. and Snyder, W. (2002) Cultivating Communities of Practice: A Guide to Managing Knowledge. Boston, MA: Harvard Business School Press.

Zimmerman, B. J. (1990) 'Self-regulated learning and academic achievement: an overview'. Educational Psychologist. 25 (1): 3-17.

Zimmerman, B. J. (1995) 'Self-regulation involves more than metacognition: a social cognitive perspective'. Educational Psychologist. 30 (4): 217-221.

\section{Notes}

${ }^{1}$ Each of the three groups digested the information for examination, but two of the three groups were instructed to use the test information to prepare for peer teaching. One of these two groups then actually carried out the student facilitator teaching session they had prepared for. The test results demonstrated significantly increased retention score results for the learners who had 
prepared for peer teaching, with the best retention for those who had prepared for and carried out the peer teaching.

\section{About the author}

Grant Petrey is a Senior Lecturer and subject leader for Animation Arts in the School of Fine Art at the University for the Creative Arts.

Email: GPetrey@ucreative.ac.uk 